Accepted manuscript (c) <2020>. This manuscript version is made available under the CC-BY-NC-ND 4.0 license http://creativecommons.org/licenses/by-nc-nd/4.0/

Published in: Journal of Synchrotron Radiation 22, 1524 (2015).

\title{
X-ray-induced Cu deposition and patterning on insulators at room temperature
}

Pei-Cheng Hsu, ${ }^{a}$ Yu-Sheng Chen, ${ }^{a}$ Yeukuang Hwu, ${ }^{\mathrm{a}, \mathrm{b}, \mathrm{c}} \mathrm{J}$. H. Je, ${ }^{\mathrm{d}}{ }^{\mathrm{G}}$. Margaritondo ${ }^{\mathrm{e}}$ and Eng Soon Tok ${ }^{\text {af }}$

a Institute of Physics, Academia Sinica, Nankang, Taipei 115, Taiwan

b Istitute of Optoelectronic Sciences, National Taiwan Ocean University, Keelung, Taiwan

c Center of Advance Optoelectronic Science, National Cheng Kung University, Tainan, Taiwan

d X-ray Imaging Center, Pohang University of Science and Technology, Pohang, Taiwan, e Faculté des Sciences de Base, Ecole Polytechnique Fédérale de Lausanne (EPFL), CH1015 Lausanne, Switzerland

f Physics Department, National University of Singapore, Singapore.

\begin{abstract}
X-ray irradiation is shown to trigger the deposition of $\mathrm{Cu}$ from solution, at room temperature, on a wide variety of insulating substrates: glass, passivated $\mathrm{Si}, \mathrm{TiN} / \mathrm{Ti} / \mathrm{SiO}_{2} / \mathrm{Si}$ and photoresists like PMMA and SU-8. The process is suitable for patterning and the products can be used as seeds for electroplating of thicker overlayers
\end{abstract}

\section{Introduction}

Copper layers cannot, as yet, be deposited from solutions at room temperature (Andricacos et al., 1998; Hsu et al., 2001), and this has severely affected applications, for example, in microelectronics. Here, we show that the problem can be overcome by stimulating the deposition with an intense X-ray bombardment. The procedure has been successfully applied to a variety of insulating substrates, from glass to $\mathrm{SiO}_{2}$ and to polymers. The deposited layers could be used to grow thicker $\mathrm{Cu}$ overlayers by electroplating. Using templates for the irradiation, the procedure could be applied to patterned overlayers. Coupled with focused X-rays (Wu et al., 2012; Chen et al., 2008), nano-patterns could be produced in air or under wet conditions (Kim et al., 2015; Lee et al., 2015).

Electrodeposition is a widely used deposition technique that has recently been extended to the fabrication of ultrasmall devices (Pisani et al., 2004; Dezuari et al., 1999; Hsu et al., 2010). Electroless deposition is another major industrial plating technique that is particularly useful for metal deposition on ultrasmall devices (Mallory \& Hajdu, 1990). Both electrodeposition and electroless deposition produce high-quality coatings (ShachamDiamand et al., 1995; Shacham-Diamand \& Dubin, 1997). Electrodeposition is, of course, difficult on insulators, and typically requires a precursor metallization (Jackson et al., 1998). In a few cases it was used to produce the seed layer but this often required surface pretreatment (Hsu et al., 2001; Horkans et al., 1984; Mallory \& Hajdu, 1990; Nagahara et al., 1993; Patterson et al., 1997, 1995). Furthermore, electroless plating is normally 
implemented at high temperature, incompatible with many substrates and high-accuracy processes.

Our solution to these problems is X-ray bombardment. This is more effective and flexible than $\gamma$-ray bombardment, for example, as far as the deposition rate and the possibility of patterning are concerned.

Our previous experiments demonstrated that X-ray irradiation induces NiP deposition on untreated insulating substrates at room temperature (Hsu et al., 2007). The reduction time and nucleation rate were accurately controlled by the electroless plating solution $\mathrm{pH}$ (Borse et al., 2004). Here, we extended the approach to the much more difficult but technologically very relevant problem of Cu deposition.

\section{Experiment}

We used three copper electroless plating solutions with different amounts of copper/hypophosphite and copper/ nickel/hypophosphite; the compositions are summarized in Table 1. Sodium hypophosphite $\left(\mathrm{NaPH}_{2} \mathrm{O}_{2} \cdot \mathrm{H}_{2} \mathrm{O}\right)$ was added as the reduction agent. The $\mathrm{pH}$ value was adjusted to 8 with sodium hydroxide. Copper sulfate $\left(180 \mathrm{~g} \mathrm{l}^{-1}\right)$ and sulfuric acid $\left(10 \mathrm{ml} \mathrm{l}^{-1}\right)$ were used for electrodeposition of thick overlayers.

Table 1

Solution composition.

\begin{tabular}{lccc} 
Component & Solution I & Solution II & Solution III \\
\hline $\mathrm{CuSO}_{4} .5 \mathrm{H}_{2} \mathrm{O}$ & 26 & 26 & 15 \\
$\mathrm{NiSO}_{4} \cdot 6 \mathrm{H}_{2} \mathrm{O}$ & $\mathrm{Nil}$ & 1 & 30 \\
$\mathrm{NaH}_{2} \mathrm{PO}_{2} . \mathrm{H}_{2} \mathrm{O}$ & 15 & 26 & 30 \\
& & & \\
\hline
\end{tabular}

As already mentioned, we performed tests with five types of insulating substrates. The substrates were prepared starting from Si wafers, except for transmission electron microscopy tests which used Au grids. The specimens were mounted in a Teflon cell containing $200 \mathrm{ml}$ of the solution.

For irradiation, we used non-monochromatized X-rays from the 01A beamline at NSRRC (National Synchrotron Radiation Research Center, Hsinchu, Taiwan) and the 7B2 beamline at the Pohang Light Source (Korea). The beam size was set to $10 \mathrm{~mm} \times 10 \mathrm{~mm}$ using slits. The irradiation time was typically $5 \mathrm{~min}$, occasionally rising to $30 \mathrm{~min}$ for thicker layers. The entire deposition process was implemented at room temperature.

An X-ray microscope was used to analyze the system during X-ray bombardment, using a specially designed Teflon cell with two thin Kapton windows. The overlayer thickness was measured with an AMBIOS XP-2 profiler. The overlayers were analyzed with a field emission scanning electron microscope (FESEM; Hitachi S-4200) also implementing energydispersive spectroscopy (EDS). A Philips CM 20 transmission electron microscope delivered structural and chemical information on overlayers deposited on Au grids. 


\section{Results and discussion}

Fig. 1 shows FESEM images of copper film on the five different substrates. We see that the substrate affected the overlayer microstructure producing granular morphologies with different grain sizes. For example, the $1.8 \mu \mathrm{m}$ Cu overlayer on glass is relatively large $(\approx 1.3$ $\mu \mathrm{m})$. On passivated $\mathrm{Si}$, the overlayer consists of small clusters with an average grain size of $195 \mathrm{~nm}$.
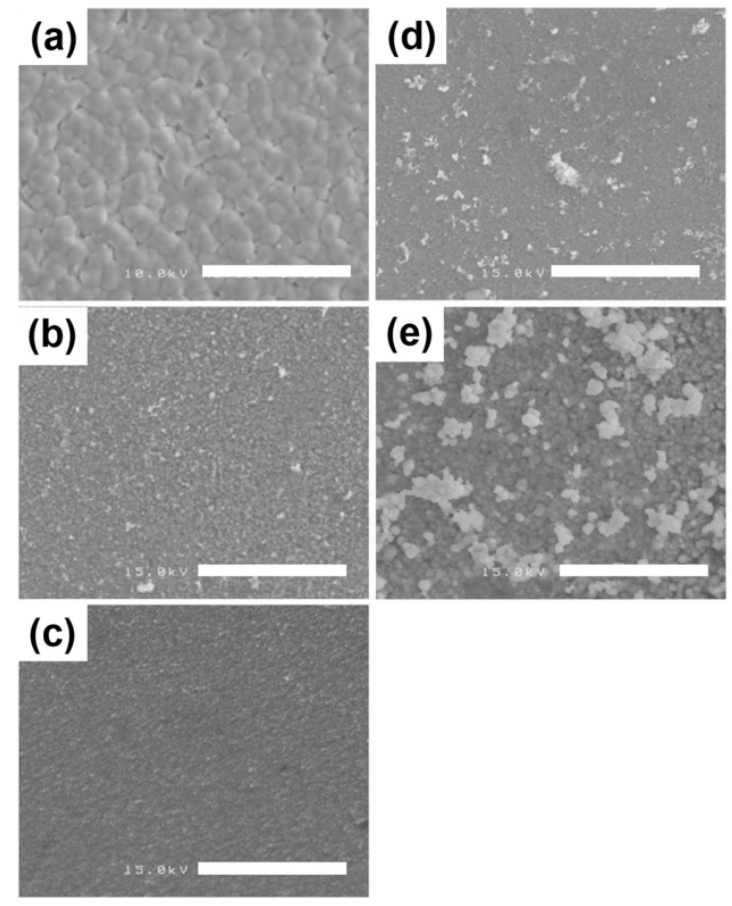

\section{Figure 1}

FESEM images showing the morphology of overlayers obtained by X-ray irradiation from solution I in Table 1 on (a) glass, (b) $\mathrm{SiO}_{2}$ on $\mathrm{Si}$, (c) $\mathrm{TiN} / \mathrm{Ti} / \mathrm{SiO}_{2} / \mathrm{Si}$, (d) PMMA photoresist and (e) SU-8 photoresist. Scale bars: $10 \mu \mathrm{m}$.

In the case of Fig. 1 (c), we directly deposited a uniform $\approx 4.5 \mu \mathrm{m}$-thick Cu overlayer with an average grain size of $152 \mathrm{~nm}$ onto a TiN/Ti/SiO$/ 2$ Si substrate without any complicated pretreatment procedure (Liu et al., 2003; Goh et al., 2002). On PMMA and SU-8, the overlayer thicknesses were $\approx 4.6$ and $\approx 4.8 \mu \mathrm{m}$, and the grain sizes were $\approx 172$ and $\approx 230 \mathrm{~nm}$, respectively; no damage to these polymer substrates was observed.

In all cases, EDS shows that the overlayers have a low phosphate content, ruling out extensive $\mathrm{Cu}-\mathrm{P}$ alloying. Specifically, the phosphate content was lower than in $\mathrm{Cu}$ overlayers co-deposited from an alkaline solution (Rondin \& Hintermann, 1970).

\subsection{Thick Cu overlayers}

The overlayers produced by X-ray irradiation are not sufficiently thick for many applications. This does not matter, however, because they can be used as seed layers for further electroplating. To demonstrate this, after X-ray irradiation we placed the samples in electroplating solution in order to perform electrodeposition at room temperature and at a 2 
A $\mathrm{dm}^{-2}$ current density. The results were positive in all cases, yielding final overlayers of thickness $>10 \mu \mathrm{m}$.

Fig. 2 shows, for example, FESEM images of an electroplated $\mathrm{Cu}$ overlayer. The copper film appears continuous with a small density of nodules. The grain size is $\approx 1 \mu \mathrm{m}$, much smaller than the seeding layer. EDS (Fig. 2c) shows a pure $\mathrm{Cu}$ content, with no contaminants such as carbon and oxygen.
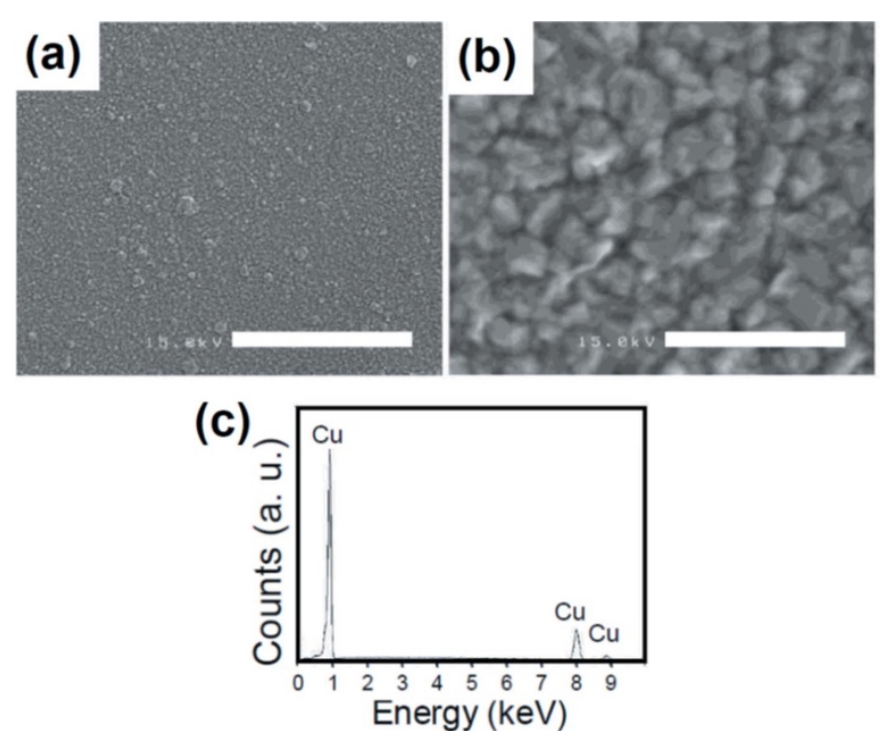

Figure 2

FESEM results showing (a) the surface morphology, (b) the micro- structure and (c) the EDS spectrum of a thick $\mathrm{Cu}$ overlayer obtained on glass, by seeding with a first layer produced with X-ray irradiation. Scale bars: $50 \mu \mathrm{m}(\mathrm{a}) ; 5 \mu \mathrm{m}$ (b).

\subsection{Patterning}

We tested the feasibility of patterning by performing X-ray bombardment through a 200 mesh Au grid. Fig. 3 shows the corresponding FESEM images. The patterned $90 \mu \mathrm{m} \times 90$ $\mu \mathrm{m}$ squares are clearly visible and have well defined edges. The homogeneous granular morphology can be used as a seed layer for further electroplating.

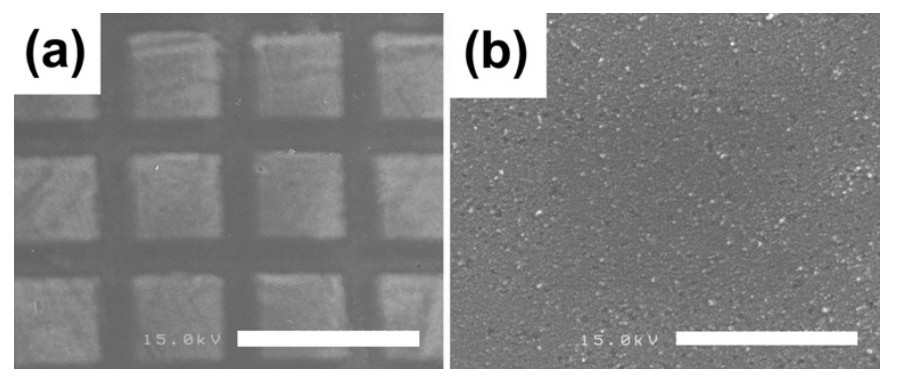

Figure 3

(a) FESEM images on a patterned $\mathrm{Cu}$ overlayer on $\mathrm{SiO}_{2} / \mathrm{Si}$. (b) High magnification view of the Cu overlayer region. Scale bars: $200 \mu \mathrm{m}(\mathrm{a}) ; 5 \mu \mathrm{m}$ (b). 


\subsection{Mechanism of X-ray-induced deposition}

We used X-ray microscopy (Wu et al., 2013) to observe in real time the reaction of individual solutions to the X-ray bombardment. For the solution with only copper sulfate, no reaction and no deposition was observed during X-ray irradiation. Only for the solution with the $\mathrm{H}_{2} \mathrm{PO}_{2}$ reduction agent was deposition observed. During the process hydrogen bubbles were observed. This suggests that the bubbles mediate the X-ray-induced deposition: one can speculate that X-rays decompose the $\mathrm{H}_{2} \mathrm{PO}_{2}$ ions allowing interaction with $\mathrm{H}_{2} \mathrm{O}$ and the production of hydrogen molecules and bubbles.

Furthermore, the deposition is characteristically different from electroless deposition of $\mathrm{Ni}$, which is a self-catalysis reaction and takes place in the solution, independent of the presence of a substrate surface. We did not succeed in the pattern deposition using X-ray masks. In the case of $\mathrm{Cu}$, the substrate plays a significant role in the reduction process of $\mathrm{Cu}$ ions and therefore leads to a patterned deposition. The reduction is also different from the other metal nanoparticle synthesis as we reported (Wang et al., 2007, 2008; Lai et al., 2013) where the reduction is exclusively from the radiolysis of solvents. Further experiments are underway to elucidate the role of substrates, and a better understanding could lead to more precise control of the deposition process, and on a wider range of metals and substrates.

\section{Acknowledgements}

This work was supported by the Ministry of Science and Technology (Taiwan), by the Academia Sinica (Taiwan), by the BK21 project, by the Korea Institute of Science and Technology Evaluation and Planning (KISTEP) through the National Research Laboratory (NRL), by the SKORE-A projects, by the Centre d'Image rie BioMedicale (CIBM) of Lausanne and by the EPFL.

\section{References}

Andricacos, P. C., Uzoh, C., Dukovic, J. O., Horkans, J. \& Deligianni, H. (1998). IBM J. Res. Dev. 42, 567-574.

Borse, P. H., Yi, J. M., Je, J. H., Tsai, W. L. \& Hwu, Y. (2004). J. Appl. Phys. 95, 1166-1170. Chen, Y. T., Lo, T. N., Chiu, C. W., Wang, J. Y., Wang, C. L., Liu, C. J., Wu, S. R., Jeng, S. T., Yang, C. C., Shiue, J., Chen, C. H., Hwu, Y., Yin, G. C., Lin, H. M., Je, J. H. \& Margaritondo, G. (2008). J. Synchrotron Rad. 15, 170-175.

Dezuari, O., Gilbert, S. E., Belloy, E. \& Gijs, M. A. M. (1999). Sensors Actuators A, 76, 349355.

Goh, W. L., Tan, K. T., Tse, M. S. \& Liu, K. Y. (2002). Int. J. Mod. Phys. B, 16, 197-204.

Horkans, J., Sambucetti, C. \& Markovich, V. (1984). IBM J. Res. Dev. 28, 690-696.

Hsu, H. H., Hsieh, C. C., Chen, M. H., Lin, S. J. \& Yeh, J. W. (2001). J. Electrochem. Soc. 148, C590-C598.

Hsu, P. C., Chu, Y. S., Yi, J. M., Wang, C. L., Wu, S. R., Hwu, Y. \& Margaritondo, G. (2010). Appl. Phys. Lett. 97, 033101.

Hsu, P. C., Wang, C. H., Yang, T. Y., Hwu, Y., Lin, C. S., Chen, C. H., Chang, L. W., Seol, S. K., Je, J. H. \& Margaritondo, G. (2007). J. Vac. Sci. Technol. A, 25, 615-620. 
Jackson, R. L., Broadbent, E., Cacouris, T., Harrus, A., Biberger, M., Patton, E. \& Walsh, T. (1998). Solid State Technol. 41, 49.

Kim, J. M., Lee, S. Y., Kang, H. C. \& Noh, D. Y. (2015). J. Synchrotron Rad. 22, 156-160.

Lai, S. F., Chien, C. C., Chen, W. C., Chen, H. H., Chen, Y. Y., Wang, C. L., Hwu, Y., Yang, C. S., Chen, C. Y., Liang, K. S., Petibois, C. \& Margaritondo, G. (2013). Biotechnol. Adv. 31, 362-268.

Lee, S. Y., Noh, D. Y., Lee, H. C., Yu, C.-J., Hwu, Y. \& Kang, H. C. (2015). J. Synchrotron Rad. 22, 781-785.

Liu, R. S., You, C. C., Tsai, M. S., Hu, S. F., Li, Y. H. \& Lu, C. P. (2003). Solid State Commun. 125, 445-448.

Mallory, G. O. \& Hajdu, J. B. (1990). Electroless Plating: Fundamentals and Applications. Orlando: American Electroplaters and Surface Finishers Society.

Nagahara, L. A., Ohmori, T., Hashimoto, K. \& Fujishima, A. (1993). J. Vac. Sci. Technol. A, 11, 763-767.

Patterson, J. C., Ni Dheasuna, C., Barrett, J., Spalding, T. R., O’Reilly, M., Jiang, X. \& Crean, G. M. (1995). Appl. Surf. Sci. 91, 124- 128.

Patterson, J. C., O’Reilly, M., Crean, G. M. \& Barrett, J. (1997). Microelectron. Eng. 33, 6573.

Pisani, M. B., Hibert, C., Bouvet, D., Beaud, P. \& Ionescu, A. M. (2004). Microelectron. Eng. 73-74, 474-479.

Rondin, J. P. \& Hintermann, H. E. A. (1970). J. Electrochem. Soc. 117, 160-167.

Shacham-Diamand, Y. \& Dubin, V. (1997). Microelectron. Eng. 33, 47-58.

Shacham-Diamand, Y., Dubin, V. \& Angyal, M. (1995). Thin Solid Films, 262, 93-103.

Wang, C. H., Chien, C. C., Yu, Y. L., Liu, C. J., Lee, C. F., Chen, C. H., Hwu, Y., Yang, C. H., Je, J. H. \& Margaritondo, G. (2007). J. Synchrotron Rad. 14, 477-482.

Wang, C. H., Liu, C. J., Wang, C. L., Hua, T. E., Obliosca, J. M., Lee, K. H., Hwu, Y., Yang, C. S., Liu, R. S., Lin, H. M., Je, J. H. \& Margaritondo, G. (2008). J. Phys. D, 41, 195301.

Wu, S. R., Hwu, Y. \& Margaritondo, G. (2012). Materials, 5, 1752- 1773.

Wu, S. R., Lin, C. H., Chen, Y. S., Chen, Y. Y., Hwu, Y., Chu, Y. S. \& Margaritondo, G. (2013). J. Phys. D, 46, 494005. 